\section{APCLUST: A versatile Apple II program to perform agglomerative hierarchical clustering analysis}

\author{
ANDREW R. GILPIN \\ University of Northern Iowa, Cedar Falls, Iowa
}

A variety of algorithms for performing agglomerative hierarchical clustering analysis have been embodied in programs on mainframe computers (Blashfield, Aldenderfer, \& Morey, 1982), but few clustering programs are available as yet for microcomputers (Whaley, 1982; recently Gilpin, 1985, described a program which performs hierarchical clustering analysis using a divisive procedure). Program APCLUST performs hierarchical clustering analyses on the Apple II family of computers.

Requirements. The program is written in APPLESOFT BASIC, a dialect of Microsoft BASIC, and should run without changes on other members of the Apple II family (II, IIe, and IIc), provided at least $48 \mathrm{~K}$ bytes of RAM are available (the program requires $28 \mathrm{~K}$ bytes of free memory). It is written to direct output to a printer if one is available, but may be used on systems lacking a printer as well. Conversion to other systems running Microsoft BASICs should be straightforward; a section of the APPLESOFT BASIC manual is devoted to relevant peculiarities of the Apple II version. A disk drive running DOS 3.3 is necessary if the file input option, discussed below, is to be used.

Input/Output Options. The program APCLUST requires as input the upper half (including diagonal) of a triangular matrix of values representing dissimilarities between pairs of up to 60 objects (variables). Data may be entered in three ways: (1) via DATA statements added to the program; (2) via entry from the keyboard during program execution; and (3) via a previously created data file on diskette (a utility program, APCLUSTFILEBUILDER, is provided to create the file). Output may be directed to the screen or to a printer in any slot (port) number. If desired, the program will pause periodically during output, awaiting a response from the user, to prevent results from scrolling off the screen. APCLUST assumes that the data matrix represents a single two/way

The author's mailing address is: Department of Psychology, University of Northern Iowa, Cedar Falls, IA 50614. one-mode proximities matrix; an additional option will transform similarity data by subtraction from the largest value in the matrix. A data editing routine is incorporated into APCLUST.

Methodology. APCLUST is an interactive implementation of Späth's (1980) algorithm, written in FORTRAN for a batch environment. Any of seven methods of analysis may be selected, including Johnson's (1967) "Min" (single-link) and "Max" (complete-link) methods; Sokal \& Sneath's (1963, p. 182) average method; three methods described by Gower (1967), using various forms of weighted averages; and Ward's (1963) procedure. Output includes a copy of the raw data matrix (and the transformed version if that option was selected), a table summarizing the clusterings and distances at which they are formed, and a dendrogram representing the same information in a tree form. Runs of APCLUST on data sets reported by Späth (1980) indicate close agreement between his program and APCLUST.

Availability. A user's manual, including program listings for APCLUST and APCLUSTFILEBUILDER, and a sample run of the former program, is available without charge by writing to the author. Copies of the program on diskette (DOS 3.3) may be obtained by sending a blank diskette plus $\$ 2$ to cover postage and handling costs (make checks payable to the University of Northern Iowa).

\section{REFERENCES}

Blashfield, R. K., Aldenderfer, M. S., \& Morey, L. C. (1982). Cluster analysis software. In P. R. Krishnaish \& L. N. Kanal (Eds.), Handbook of statistics, Vol. 2: Classification, pattern recognition, and reduction of dimensionality. Amsterdam: North-Holtand.

GiLPIN, A. R. (1985). APPLECOR: An Apple II implementation of hierarchical clustering analysis using the CONCOR algorithm. Behavior Research Methods, Instruments, \& Computers, 17, 140.

Gower, J. C. (1967). A comparison of some methods of cluster analysis. Biometrics, 23, 623-637.

Johnson, S. C. (1967). Hierarchical clustering schemes. Psychometrika, 32, 241-254.

SokAl, R. R., \& SNeath, P. H. A. (1963). Principles of numerical taxonomy. New York: Freeman.

SPÄTH, H. (1980). Cluster analysis algorithms for data reduction and classification of objects. Chichester, West Sussex, England: Ellis Horwood.

WARD, J. H. (1963). Hierarchical grouping to optimize an objective function. Journal of the American Statistical Association, 58, 236-244.

WhALEY, C. P. (1982). Interactive clustering. Behavior Research Methods \& Instrumentation, 14, 170-175.

(Revision accepted for publication May 31, 1985.) 